\title{
Estimativa de propriedades termofísicas em campo usando modelos de transferência de calor e umidade
}

\author{
Estimation of field thermo-physical using heat and \\ moisture transfer models
}

\section{Martin Ordenes \\ Saulo Guths \\ Roberto Lamberts}

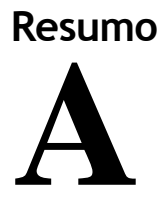

condução de calor através dos componentes opacos da envoltória é um dos parâmetros que caracterizam o desempenho térmico das edificações e suas consequências em termos de consumo energético e conforto térmico. A envoltória pode ser descrita termicamente a partir de dois parâmetros: a condutividade térmica $(\lambda)$; e a capacidade térmica volumétrica $(\rho \cdot c)$. Estimar essas propriedades termofísicas em campo permite caracterizar elementos construtivos considerando aspectos como comportamento térmico em condições climáticas específicas, variação na qualidade de materiais, soluções locais de construção e desgaste de materiais. Este trabalho apresenta um método para estimar $\lambda$ e $\rho \cdot c$ em elementos homogêneos usando um teste não destrutivo que aproveita as oscilações naturais do clima. A temperatura e o calor superficial são medidos em uma amostra de concreto (com propriedades conhecidas) e os dados são tratados com uma técnica de processamento de sinal. A estimativa é executada com um modelo de transferência de calor e umidade integrado. As medições foram realizadas em seis dias durante um período de um mês, registrando dias com diferentes condições de céu, visando mostrar a importância da radiação solar como fonte de calor. Os resultados apresentaram

Martin Ordenes Laboratório de Eficiência Energética em Edificações Universidade Federal de Santa Catarina

Caixa-Postal 476 Trindade

Florianopolis - SC - Brasil CEP 88040-900

Tel.: (48) 331-5184 E-mail: martin@labeee.ufsc.br

Saulo Guths Laboratório de Eficiência Energética em Edificações Universidade Federal de Santa Catarina Tel.: (48) 3721-7709 E-mail: saulo@lmpt.ufsc.br

Roberto Lamberts Laboratório de Eficiência Energética em Edificações Universidade Federal de Santa Catarina Tel.: (48) 3721-7709 E-mail: lamberts@ecv.ufsc.br

Recebido em 04/03/10 Aceito em 01/10/10 uma diferença de 10-14\% na estimativa das propriedades termofísicas.

Palavras-chave: Ensaio não destrutivo. Estimativa de propriedades termofísicas. Modelo de transferência de calor e umidade.

\section{Abstract}

Conduction heat transfer through opaque envelope components is one of the parameters that characterize the thermal performance of buildings and its consequences in terms of energy consumption and thermal comfort. A building envelope can be thermally described by two parameters: thermal conductivity $(\lambda)$ and heat capacity $(\rho \cdot c)$. Estimating these thermal properties in situ allows the characterization of real building elements considering different aspects such as thermal behaviour under specific weather conditions, quality variability in materials, local construction technologies and material deterioration. This paper presents a method to estimate the thermal conductivity and volumetric heat capacity of a homogeneous element using a non-destructive test considering natural oscillations. Surface temperature and heat flow were measured in a concrete sample (with known thermal properties) and data was treated with a signal processing technique. Estimation is carried out with a heat and moisture transfer model. The measurements were performed on six days under different sky conditions over a month period, showing the importance of solar radiation as a heat source. Results gave acceptable estimations (average inaccuracy of 10-14\%) of thermo-physical properties.

Keywords: Non-destructive test. Thermo physical properties estimation. Heat and moisture simulation. 


\section{Introdução}

A motivação para realizar este trabalho surgiu da necessidade de desenvolver um método capaz de obter simultaneamente a condutividade térmica $(\lambda)$ e a capacidade térmica volumétrica $(\rho \cdot c)$, a partir de um ensaio não destrutivo que utilize as informações contidas nas oscilações climáticas, que seja fácil de implementar e que necessite apenas um equipamento simplificado.

Estimar essas propriedades termofísicas em campo permite caracterizar componentes construtivos em situações mais próximas à realidade da edificação, isto é, considerando seu desempenho sob condições climáticas específicas, as variações na qualidade dos materiais construtivos, as diferentes técnicas de construção local e o desgaste dos materiais. No Brasil, estão sendo realizados esforços para avaliar em campo o desempenho térmico de diferentes soluções construtivas para a cobertura (MICHELS; LAMBERTS; GUTHS, 2008), e este trabalho pretende ser uma contribuição para avaliar os elementos opacos verticais na envolvente.

Os efeitos de calor geram uma distribuição não homogênea no conteúdo de umidade (em consequência nas propriedades térmicas). Essa situação deve ser considerada para determinar propriedades equivalentes que representem o componente de forma global.

O objetivo do trabalho é desenvolver um método de estimativa simultânea para a condutividade térmica $(\lambda)$ e a capacidade térmica volumétrica $(\rho \cdot c)$. O algoritmo de estimativa considera mecanismos de transferência de calor e umidade. O método foi desenvolvido de forma que possa ser implementado em campo mediante um ensaio não destrutivo com medições nas oscilações de temperatura e fluxo de calor nas superfícies do componente (sinal natural) devidas às variações climáticas.

\section{Revisão da literatura}

\section{Métodos anteriores aplicados em campo}

A revisão bibliográfica mostra que a estimativa de propriedades termofísicas em campo vem sendo desenvolvida desde os anos 70, com a introdução do Envelope Thermal Test Unit (CONDON; CARROL; SONDEREGGER, 1979) e, posteriormente, com o Large Scale Climate Simulator, utilizado em testes de laboratório (BECK; PETRIE; COURVILLE, 1991). Recentemente, a solução no domínio da frequência para a equação de transferência de calor tem sido aplicada em diferentes métodos para melhorar o desempenho de muros Trombe (ZALEWSKI et al., 1997), para identificar a capacidade térmica efetiva de componentes cerâmicos (AKANDER, 2000), para destacar anomalias internas em paredes de concreto (DEFER et al., 2002) e para estimar as propriedades térmicas de componentes de PVC (BORGES; LIMA E SILVA; GUIMARÃES, 2006).

A identificação simultânea das propriedades termofísicas $(\lambda$ e $\rho \cdot c)$ em campo pode ser realizada de forma não destrutiva utilizando-se os procedimentos descritos por Gustafsson (1990) e Takahashi et al. (2004). Esses métodos apresentam vantagens, pois requerem alguns segundos como tempo de ensaio, não exigem planicidade de uma superfície ampla $(50-200 \mathrm{~mm})$ e podem ser aplicados em diferentes materiais, como vidros, plásticos, cerâmicos e metais. Porém, a suposição de um material semi-infinito no algoritmo de estimativa (e o breve tempo de ensaio) limita o estudo de componentes às primeiras camadas de superfície (10-15 mm).

A norma ISO 9869 (ISO, 1994) apresenta um procedimento de medição em campo para estimar a resistência térmica e a transmitância térmica, que visa a entender a envoltória da edificação como um elemento de isolamento térmico. Desde que a resistência térmica e a transmitância térmica são propriedades a serem obtidas em condições de regime permanente e essa condição dificilmente é observada em campo, a norma propõe dois métodos de análise teórica do fluxo de calor e temperatura superficial registrada para reduzir o erro nos resultados calculados. Essa norma foi aplicada em diferentes trabalhos de pesquisa (DIMOUDI; LYKOUDIS; ANDROUTSOPOULOS, 2006; HARALAMBOPOULOS; PAPARSENOS, 1998; NICOLAJSEN, 2005).

No entanto, nenhum desses métodos considera a influência do conteúdo de umidade nos fenômenos de transferência de calor. A ferramenta para estimativa de propriedades termofísicas desenvolvida neste trabalho utiliza como base o modelo higrotérmico apresentado por Philip e DeVries (1957).

\section{Módelo Philip e Devries para transferência de calor e umidade}

Abordando a transferência de massa (umidade) do ponto de vista macroscópico, utiliza-se o modelo fenomenológico desenvolvido por Philip e De Vries (1957). Esse modelo permite caracterizar o transporte de umidade em meios insaturados 
através de mecanismos clássicos de difusão de vapor e movimento de líquido por capilaridade.

Nesse modelo, as equações diferenciais parciais governantes são derivadas das equações de difusão de calor e a formulação de Fick para difusão de um fluido. Elas são adaptadas para a conservação de umidade e calor em um elemento de volume diferencial para um material poroso.

A relação de conservação de energia é definida como:

$$
\rho_{0} \cdot c_{m}(T, \theta) \cdot \frac{d T}{d t}=\frac{d}{d x}\left(\lambda_{m}(T, \theta) \cdot \frac{d T}{d x}\right)-L(T) \cdot \frac{d j_{v}}{d x} \text { Eq. } 1
$$

Onde:

$\rho_{\mathrm{o}}$ é a densidade da matriz sólida;

$\mathrm{c}_{\mathrm{m}}$ e $\lambda_{\mathrm{m}}$ representam os valores médios para o calor específico e a condutividade térmica

respectivamente em condição úmida;

$\mathrm{L}$ representa o calor latente de vaporização;

$\mathrm{j}_{\mathrm{v}}$ representa o fluxo de vapor;

$\mathrm{T}$ é a temperatura;

t é o tempo; e

$\mathrm{x}$ é a posição.

$\mathrm{Na}$ Equação 1, observa-se que a relação de conservação de energia com umidade integrada se diferencia da equação de difusão de calor pelo termo fonte (L), que representa o calor envolvido na mudança de fase do líquido dentro do meio poroso.

Uma vez que a equação de difusão de calor define a condutividade térmica $(\lambda)$ e a capacidade térmica volumétrica $(\rho \cdot c)$ como valores constantes para toda a espessura do componente, ela pode ser considerada linear e os cálculos mais diretos. Quando o componente é considerado como um meio poroso não saturado, cada volume infinitesimal do componente possui determinada condutividade térmica $\left(\lambda_{\mathrm{m}}\right)$ e capacidade térmica volumétrica $\left(\rho_{\mathrm{o}} \cdot c_{\mathrm{m}}\right)$, que dependem da temperatura e do conteúdo de umidade.

Para o caso unidirecional, a equação de conservação de umidade é descrita como:

$\frac{d \theta}{d t}=-\frac{d}{d x}\left(\frac{j}{\rho_{l}}\right)$

Eq. 2

Onde:

$\theta$ representa o conteúdo volumétrico de umidade e $\rho_{\mathrm{l}}$ a densidade do fluido em fase líquida.

O fluxo total de massa (j) pode ser representado pela soma das fases líquida e gasosa como:
$\frac{j}{\rho_{l}}=-D_{T} \cdot \frac{d T}{d x}-D_{\theta} \cdot \frac{d \theta}{d x}$

Eq. 3

Onde:

Os coeficientes de transporte representam a soma de cada uma das fases (líquida e gasosa);

$\mathrm{D}_{\mathrm{T}}$ é o coeficiente de transporte por diferença de temperatura; e

$\mathrm{D}_{\theta}$ é o coeficiente de transporte por diferença de conteúdo de umidade.

O fluxo de vapor unidirecional também pode ser descrito a partir dos coeficientes de transporte $\left(\mathrm{D}_{\mathrm{Tv}}\right.$ e $\mathrm{D}_{\theta \mathrm{v}}$ ) como:

$$
\frac{j_{v}}{\rho_{l}}=-D_{T_{v}} \cdot \frac{d T}{d x}-D_{\theta v} \cdot \frac{d \theta}{d x}
$$

\section{Metodologia}

\section{Modelagem higrotérmica em regime transiente}

As equações de balanço higrotérmico, fluxo de umidade e fluxo de vapor foram resolvidas pelo método implícito de diferenças finitas.

Assim, a equação de conservação de energia (1) é discretizada para cada ponto interno (i) como:

$$
\begin{aligned}
& \Delta x \cdot \rho_{0} \cdot c_{m} \cdot \frac{T_{i}-T_{i}^{0}}{\Delta t}=\lambda_{e} \cdot \frac{T_{i-1}-T_{i}}{\Delta x}+\lambda_{d} \cdot \frac{T_{i+1}-T_{i}}{\Delta x}+ \\
& +L\left(T_{i}\right) \cdot \rho_{l} \cdot\left(D_{T v e} \cdot \frac{T_{i-1}-T_{i}}{\Delta x}+D_{T v d} \cdot \frac{T_{i+1}-T_{i}}{\Delta x}+D_{\theta e l} \cdot \frac{\theta_{i-1}-\theta_{i}}{\Delta x}+D_{\theta d d} \cdot \frac{\theta_{i+1}-\theta_{i}}{\Delta x}\right)
\end{aligned}
$$

O calor latente de vaporização $\left(\mathrm{L}\left(\mathrm{T}_{\mathrm{i}}\right)\right)$ é calculado em cada ponto a partir da regressão linear usando os valores tabelados por Incropera e DeWitt (2003) para uma faixa de temperaturas entre $0{ }^{\circ} \mathrm{C}$ e $100{ }^{\circ} \mathrm{C}$ como:

$L\left(T_{i}\right)=-2,188 T_{i}+2475,8$

Eq. 6

A capacidade térmica volumétrica para cada volume infinitesimal $\left(\rho_{\mathrm{o}} \cdot \mathrm{c}_{\mathrm{m}}\right)$ pode ser calculada como uma função linear do conteúdo de umidade líquida em que o calor específico do vapor de água não será considerado:

$\rho_{0} \cdot c_{m}=\rho_{0} \cdot c_{0}+\rho_{0} \cdot c_{l} \cdot w_{l}$

Eq. 7

Considerando que:

$w_{l}=\frac{\rho_{l}}{\rho_{0}} \cdot \theta_{l}$

Eq. 8

$\rho_{0} \cdot c_{m}=\rho_{0} \cdot c_{0}+\rho_{l} \cdot c_{l} \cdot \theta_{l}$

Para definir os valores para a densidade da água líquida $\left(\rho_{\mathrm{l}}=990 \mathrm{~kg} / \mathrm{m}^{3}\right)$ e do calor específico da água $\left(\mathrm{c}_{1}=4.180 \mathrm{~J} / \mathrm{kg} \mathrm{K}\right)$, foram considerados os 
valores médios dos dados apresentados por Incropera e De Witt (2003) para uma faixa de temperatura entre $15^{\circ} \mathrm{C}$ e $65^{\circ} \mathrm{C}$.

A equação de conservação de massa (2) pode ser discretizada como:

$\Delta x \cdot \frac{\theta_{i}-\theta_{i}^{0}}{\Delta t}=D_{T e} \cdot \frac{T_{i-1}-T_{i}}{\Delta x}+D_{T d} \cdot \frac{T_{i+1}-T_{i}}{\Delta x}+D_{\theta t} \cdot \frac{\theta_{i-1}-\theta_{i}}{\Delta x}+D_{\theta i} \cdot \frac{\theta_{i+1}-\theta_{i}}{\Delta x}$

Eq. 10

Os termos $\lambda, \mathrm{D}_{\mathrm{Tv}}, \mathrm{D}_{\theta \mathrm{v}}, \mathrm{D}_{\mathrm{T}}$ e $\mathrm{D}_{\theta}$ nas Equações $5 \mathrm{e}$ 10 possuem sufixos "e" e "d" para denotar as características de transporte vizinhas ao ponto $\mathrm{p}$ (esquerda e direita respectivamente), que são calculadas como a média harmônica entre o ponto interno (i) e seu vizinho. Os coeficientes de transporte de umidade são definidos de acordo com a amostra de argamassa estudada por Perrin (1985), em virtude de a amostra utilizada neste trabalho de pesquisa ser de concreto e apresentar condições de porosidade similares. A Figura 1 apresenta os valores para $D_{T}, D_{T v}, D_{\theta}$ e $D_{\theta v}$ de acordo com os valores observados por Perrin (1985). Observa-se na Figura 1 que as variações de umidade por gradiente de temperatura são consequência quase exclusivamente do fluxo de vapor, já que $\mathrm{D}_{\mathrm{T}}=\mathrm{D}_{\mathrm{Tv}}$ para uma saturação abaixo de $70,0 \%$. Essa situação também se observa para o gradiente de conteúdo de umidade em saturação abaixo de $7,0 \%$.

O sistema é resolvido para cada intervalo de tempo, começando pelo cálculo da distribuição de temperaturas e usando esse resultado como dado de entrada para o algoritmo TDMA de umidade. Em seguida, a distribuição de conteúdo de umidade calculada é usada para calcular uma nova distribuição de temperaturas, também pelo método TDMA. Esse procedimento é repetido iterativamente para cada intervalo de tempo. Para garantir a precisão dos resultados, o algoritmo é resolvido iterativamente em cada intervalo de tempo até atingir um critério de convergência de $10^{-5}$ para a temperatura $\left(\mathrm{T}_{\mathrm{i}}\right)$ e o conteúdo de umidade $\left(\theta_{\mathrm{i}}\right)$ em cada nó.

Outro parâmetro que caracteriza o comportamento higroscópico do material é a curva de adsorção, que representa a capacidade que tem o material (de acordo com o volume de poros e permeabilidade) de reter e aumentar o conteúdo de umidade nos poros em função da umidade relativa do ar para uma condição de temperatura ambiente constante. A Figura 2 apresenta a isoterma de adsorção obtida por Perrin (1985) para a argamassa. Esse material possui uma distribuição de poros com diâmetros entre $20 \AA$ e $500 \AA$. Isso confere um comportamento altamente higroscópico, como pode ser observado na Figura 2.

\section{Participação do calor latente na identificação da condutividade térmica}

Para realizar a estimativa dessas propriedades termofísicas, é necessário considerar um pulso de calor como estímulo. A partir da resposta do componente, é possível determinar suas propriedades termofísicas. Inicialmente, o componente pode ser considerado como um meio poroso insaturado homogêneo e isotrópico. No entanto, se o pulso de calor for mantido por um tempo prolongado, o componente começará a apresentar uma distribuição não homogênea no conteúdo de umidade, o que acaba afetando as propriedades termofísicas nas camadas superficiais das amostras e deve ser considerado na identificação de parâmetros térmicos que representem o componente de forma global.

O comportamento higroscópico de um componente de argamassa foi simulado através das equações apresentadas em Aplicação do método em campo, para uma situação simplificada de regime transiente, isto é, uma condição em que se passa de um estado de equilíbrio isotérmico inicial para um estado estacionário com gradiente térmico devido a um fluxo de calor constante imposto em uma das superfícies. Essas condições representam o procedimento usado para determinar a resistência térmica de materiais pela norma NBR 15220-4 (ABNT, 2005). No entanto, as simulações permitem observar a distribuição interna de temperatura e conteúdo de umidade no componente entre esses dois estados. A Tabela 1 apresenta os valores que definem as condições de procedimento para a simulação de um componente de argamassa com $50 \mathrm{~mm}$ de espessura. 


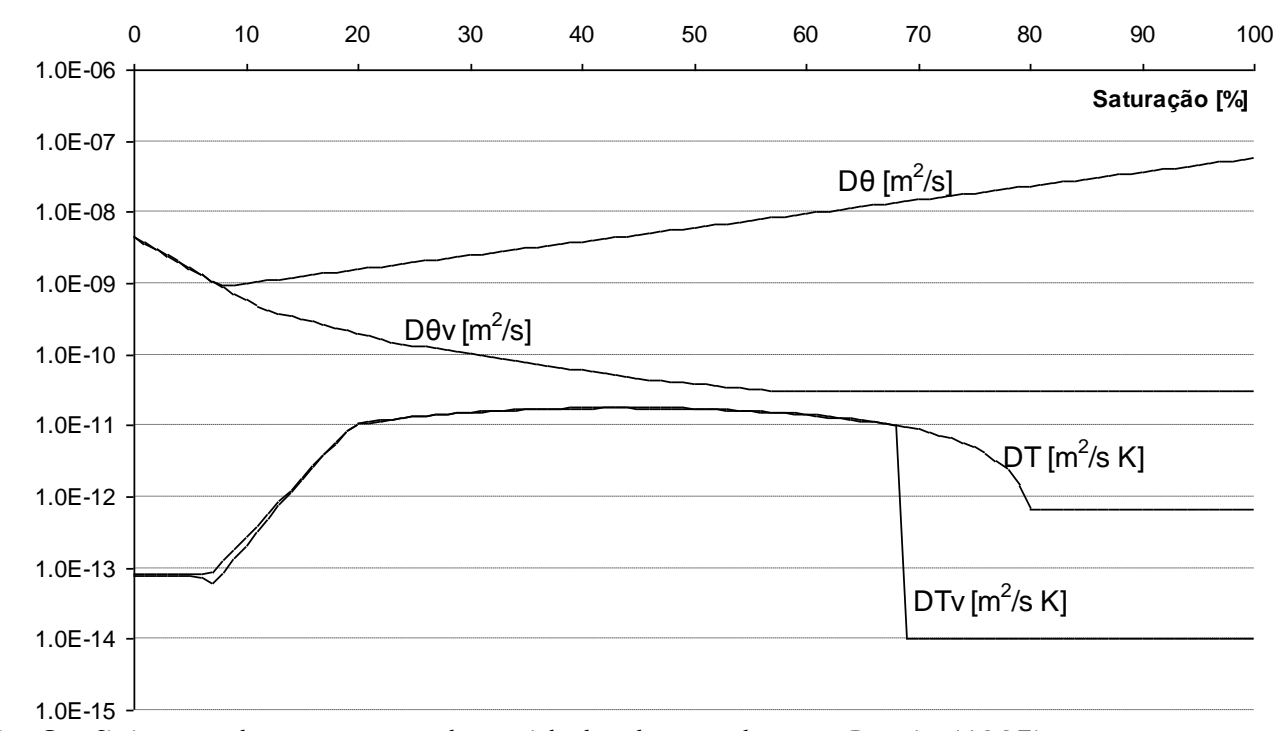

Figura 1 - Coeficientes de transporte de umidade observados por Perrin (1985) para a argamassa

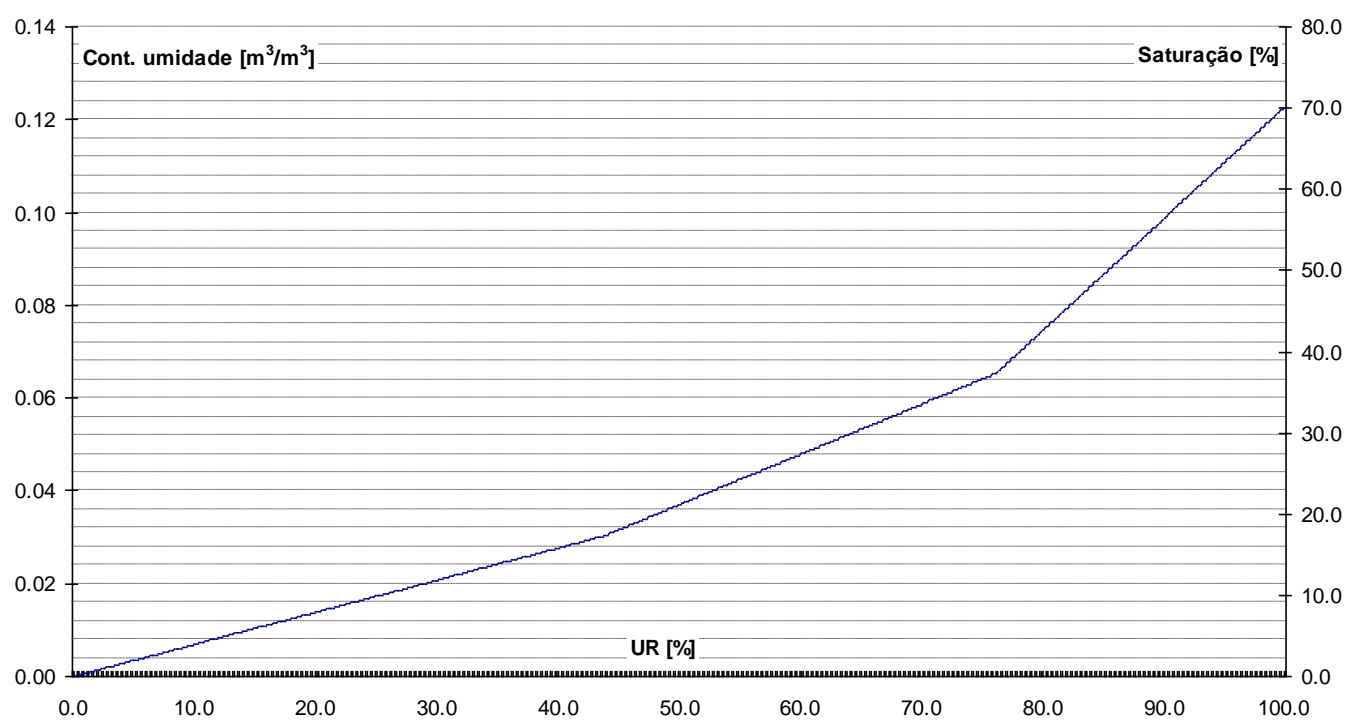

Figura 2 - Isoterma de adsorção observada por Perrin (1985) para o material de argamassa

\begin{tabular}{l|c}
\hline \multicolumn{2}{c}{ Condições definidas na simulação } \\
\hline $\mathrm{q} "\left[\mathrm{~W} / \mathrm{m}^{2}\right]$ (superfície quente) & 350,0 \\
\hline $\mathrm{T}\left[{ }^{\circ} \mathrm{C}\right]($ superfície fria) & 15,0 \\
\hline$\Theta_{\mathrm{o}}\left[\mathrm{m}^{3} / \mathrm{m}^{3}\right]$ & 0,0492 \\
\hline $\mathrm{j}\left[\mathrm{kg} / \mathrm{m}^{2} \mathrm{~s}\right]$ (sup. quente e fria) & 0,0 \\
\hline$\Delta \mathrm{x}[\mathrm{mm}]$ & 0,1 \\
\hline$\Delta \mathrm{t}[\mathrm{s}]$ & 1,0 \\
\hline
\end{tabular}

Tabela 1 - Condições iniciais, de contorno e de discretização usadas nas simulações com argamassa

A distribuição de umidade determina as variações das propriedades termofísicas nas camadas internas do componente de argamassa. As Figuras $3 \mathrm{a}$ e $3 \mathrm{~b}$ apresentam a distribuição da condutividade térmica e da capacidade térmica volumétrica respectivamente. Observa-se nas duas figuras que as variações acompanham a distribuição de umidade no componente, em que a superfície quente vai diminuindo seu conteúdo de umidade e diminuído os valores das propriedades térmicas. O contrário acontece na superfície fria em virtude do aumento no grau de saturação de poros. Para o tempo final de simulação (curva $3[\mathrm{~h}]$ ), a amplitude de variação nas camadas superficiais é de $1,15 \%$ para a condutividade térmica e de $1,05 \%$ para a capacidade térmica volumétrica. 
Ao calcular o fluxo de calor usando a diferença de temperatura entre as superfícies $(\Delta \mathrm{T})$ obtida nas simulações com a condutividade térmica efetiva e a espessura do material através da equação de Fourier $(\mathrm{q} "=\lambda \cdot \Delta \mathrm{T} / \mathrm{l})$, o valor obtido não coincide com o fluxo de calor imposto nas condições de contorno.

Isso ocorre porque, na equação de Fourier, é considerado somente o calor transferido por fenômenos de condução através do componente. Essa consideração pode ser aplicada diretamente quando se trabalha com um modelo exclusivamente térmico. No entanto, em ensaios de laboratório, os fenômenos de transferência de umidade interferem na composição do fluxo de calor.

A Figura 4 apresenta a composição do fluxo de calor ao longo do tempo para a superfície fria na simulação com o material de argamassa estudado por Perrin (1985). Nela, observa-se que a maior parte dos $350 \mathrm{~W} / \mathrm{m}^{2}$ é transferida por condução. No entanto, para esse caso, uma parcela de calor latente (1-2\%) também participa das trocas térmicas para realizar a mudança de fase no conteúdo de umidade. Na superfície fria, a frente de calor chega ao começo por condução, e o calor latente vai ganhando importância ao longo da simulação, conforme a frente de vapor alcança essa superfície (espessura $=50 \mathrm{~mm}$ ).

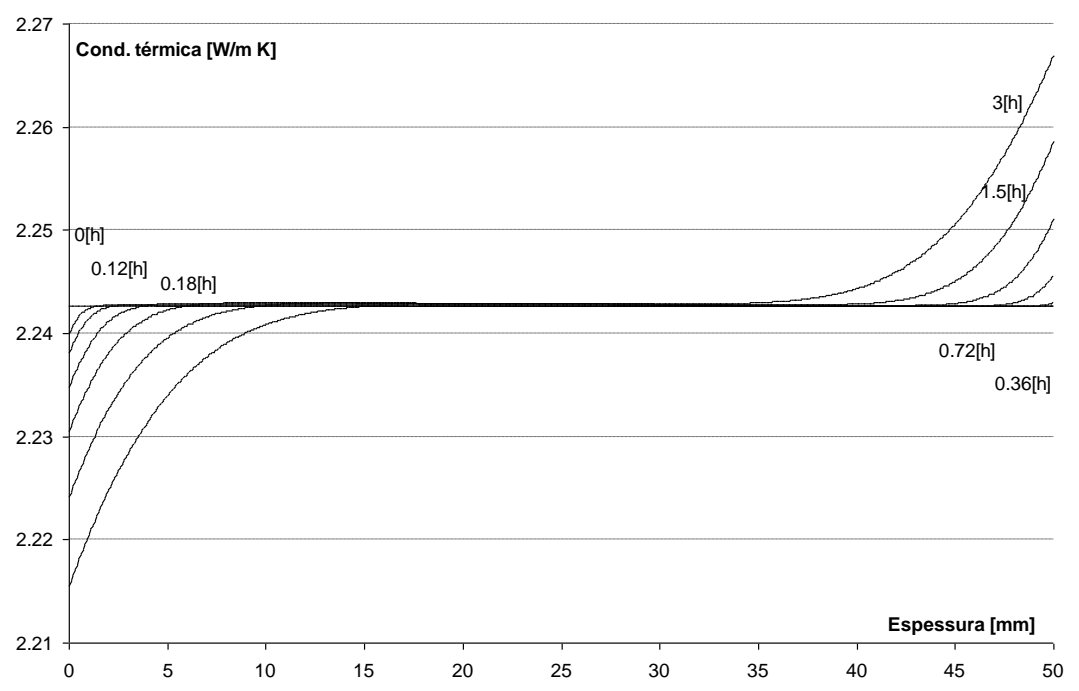

(a)

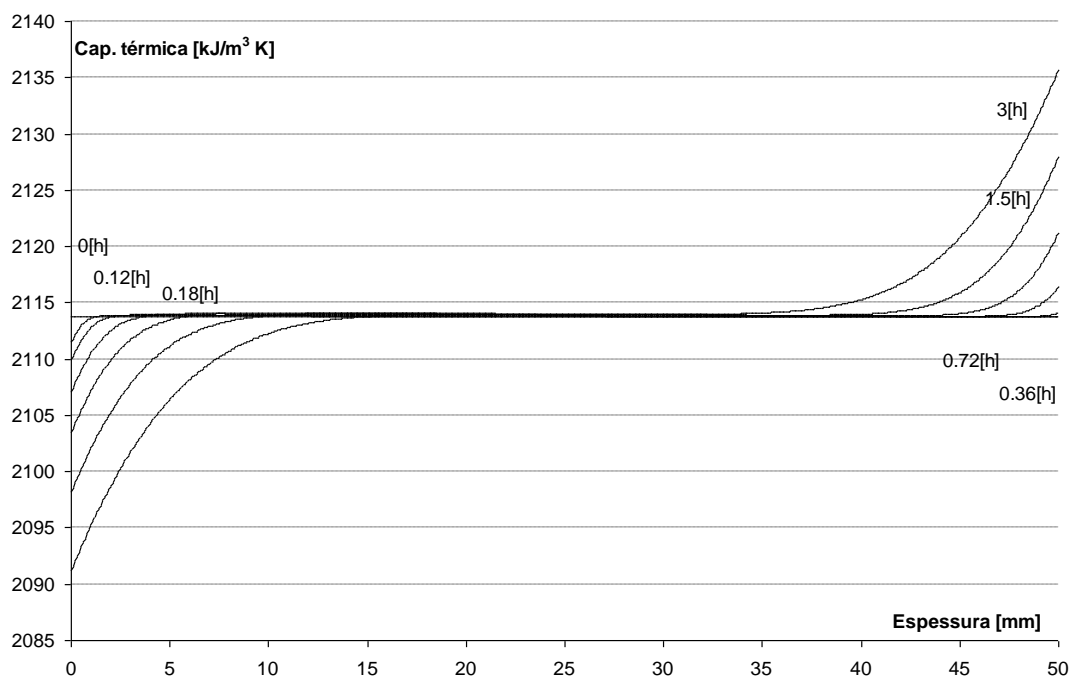

(b)

Figura 3 - Distribuição da condutividade térmica (a) e da capacidade térmica volumétrica (b) no perfil do componente de argamassa 
Para a Figura 4 também foram calculadas as trocas de calor por destilação de líquido e entalpia, de acordo com o trabalho de De Vries (1958). Porém, observa-se que a participação desses fenômenos é pouco expressiva.

Na prática, os sensores de fluxo de calor colocados nas superfícies não conseguem diferenciar o calor que chega por condução ou por vaporização (latente), o que gera diferenças no cálculo da condutividade térmica. Continuando com o exemplo apresentado na Figura 4, a condutividade térmica experimental calculada consideraria o fluxo total de calor $\left(\mathrm{q} "=350 \mathrm{~W} / \mathrm{m}^{2}\right)$ e a diferença de temperatura observada $\left(\Delta \mathrm{T}=4,7^{\circ} \mathrm{C}\right)$. Assim, usando a relação de regime permanente $(\mathrm{q} "=\lambda \cdot \Delta \mathrm{T} / \mathrm{l})$, a condutividade térmica experimental calculada seria de $2,275 \mathrm{~W} / \mathrm{m} \mathrm{K}$. Esse valor apresenta uma diferença de $1,5 \%$ se comparado à condutividade térmica efetiva usada nas simulações $(2,243 \mathrm{~W} / \mathrm{m} \mathrm{K})$.
A Figura 5 apresenta as diferenças percentuais $(\Delta \lambda)$ entre a condutividade térmica experimental e a condutividade térmica efetiva para materiais simulados com diferentes valores para a condutividade térmica da matriz sólida, isto é, a argamassa (curvas $\lambda=1,92[\mathrm{~W} / \mathrm{m} \mathrm{K}]$ e $\lambda=0,84$ $[\mathrm{W} / \mathrm{m} \mathrm{K}])$ com diferentes níveis de saturação. Nas duas curvas, observa-se que, para valores de saturação menores que $10 \%$, o conteúdo de umidade no componente não é suficiente para gerar uma diferença significativa. A partir desse valor, as diferenças começam a aumentar, chegando a um valor máximo entre $30 \%$ a $40 \%$ de saturação. Para uma saturação acima de $60 \%$, as curvas apresentam uma queda brusca, pois o volume de poros começa a ter um conteúdo de líquido importante, o que dificulta o avanço de um fluxo de vapor. Dessa forma, o calor latente perde importância e a diferença entre a condutividade térmica experimental e a condutividade térmica efetiva diminui.

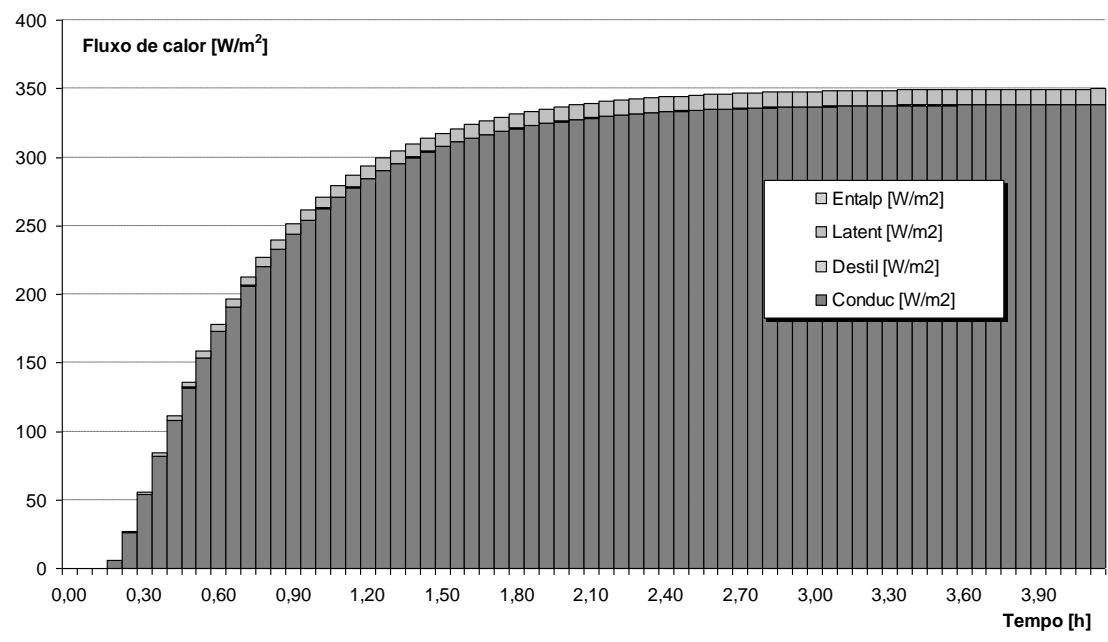

Figura 4 - Composição do fluxo de calor na superfície fria

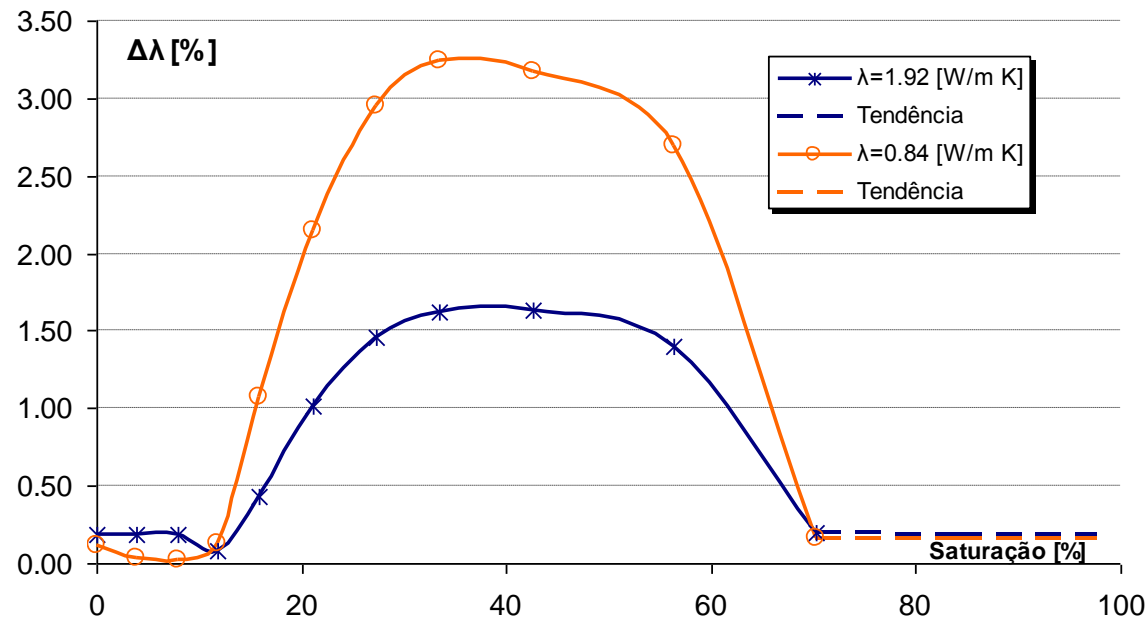

Figura 5 - Diferença entre a condutividade térmica experimental e a efetiva $(\Delta \lambda)$ para os componentes simulados em função da saturação 


\section{0 programa $\mathrm{kc}_{\text {úmido }}$ para a estimativa de propriedades térmicas}

O modelo integrado de transferência de calor e umidade é inserido no código do programa $\mathrm{kC}_{\text {úmido }}$ para estimativa de propriedades termofísicas. Essa estimativa considera as diferenças nas condições higrotérmicas das camadas superficiais decorrentes da distribuição de umidade nos poros. Assim, a estimativa de propriedades termofísicas fornece um resultado global que representa toda a espessura do componente construtivo. Ainda, a integração dos fenômenos de transferência de umidade no programa $\mathrm{kC}_{\text {úmido }}$ permite estimar as propriedades termofísicas em condições secas e úmidas.

$\mathrm{Na}$ identificação das propriedades termofísicas, é utilizado o mecanismo de busca exaustiva como método de otimização dentro de uma faixa de variação para a condutividade térmica e a capacidade térmica volumétrica, definida pelo usuário $\left(\lambda_{\max }, \quad \lambda_{\min }, \quad \rho \bullet^{\bullet} c_{\max }, \quad \mathrm{e} \quad \rho \bullet c_{\min }\right)$. A determinação do valor para cada propriedade térmica vem dada pela discretização de cada propriedade térmica dentro do intervalo $\left(\lambda_{\text {step }}\right.$, $\rho \bullet c_{\text {step }}$ ) como:

$$
\begin{aligned}
& \lambda_{o}=\lambda_{\min }+n \cdot \lambda_{\text {step }} \text { para } \lambda_{s c} \leq \lambda_{\max } \\
& \rho \cdot c_{o}=\rho \cdot c_{\min }+n \cdot \rho \cdot c_{\text {step }} \text { para } \\
& \rho \cdot c_{s c} \leq \rho \cdot c_{\max }
\end{aligned}
$$

Onde:

$\lambda_{\mathrm{o}}$ e $\rho \cdot c_{\mathrm{o}}$ representam as propriedades termofísicas do componente para a condição seca.

Em seguida, a condutividade térmica úmida $\left(\lambda_{\mathrm{m}}\right)$ para cada volume infinitesimal é ajustada de acordo com a saturação, em que a curva determinada em laboratório é deslocada em função da condutividade térmica seca. Para a capacidade térmica volumétrica, o valor úmido $\left(\rho^{\bullet} c_{\mathrm{m}}\right)$ é calculado a partir da Equação 9.

As equações no método implícito por diferenças finitas para resolver o sistema integrado de transferência de calor e umidade serão utilizadas para cada combinação de condutividade e capacidade térmica volumétrica úmidas $\left(\lambda_{\mathrm{m}} \mathrm{e}\right.$ $\left.\rho^{\bullet} \mathrm{c}_{\mathrm{m}}\right)$, estabelecendo como propriedades do material aquela combinação que apresentar a menor diferença entre os mínimos quadrados relativos de valores calculados e valores medidos em cada superfície (Equações 13 e 14). No cálculo de mínimos quadrados, o programa $\mathrm{kC}_{\text {úmido }}$ desconsidera o período inicial correspondente a $5,0 \%$ do tempo total de medição, a fim de evitar diferenças importantes entre os valores calculados e medidos produzidas pelas condições iniciais definidas pelo usuário.

$$
\begin{gathered}
\Delta T_{S}=\frac{\sum_{i=0,05 \cdot P}^{i=P} \sqrt{\left(T_{S}(i)_{\text {medido }}-T_{S}(i)_{\text {calculado }}\right)^{2}}}{\left|\sum_{i=0,05 \cdot P}^{i=P} T_{S}(i)_{\text {medido }}\right|} \\
\Delta q^{\prime \prime}{ }_{S}=\frac{\sum_{i=0,05 \cdot P}^{i=P} \sqrt{\left(q^{\prime \prime}{ }_{S}(i)_{\text {medido }}-q^{\prime \prime}{ }_{S}(i)_{\text {calculado }}\right)^{2}}}{\left|\sum_{i=0,05 \cdot P}^{i=P} q^{\prime \prime}(i)_{\text {medido }}\right|}
\end{gathered}
$$

\section{Caracterização da amostra de concreto}

Trata-se de um lote de amostras fabricadas de forma homogênea com concreto autoadensável. O concreto autoadensável (CAA) tem como principal característica grande fluidez, ou seja, alta trabalhabilidade, podendo ser moldado em formas e preencher cada espaço vazio através de seu peso próprio, não necessitando de qualquer tipo de vibração ou compactação externa. Os materiais utilizados para produção de CAA são os mesmos utilizados para a produção de concretos convencionais, porém com maior adição de finos e de aditivos plastificantes.

Utilizando esse traço, foram fabricadas 4 amostras de concreto com $30 \mathrm{~cm}$ x $30 \mathrm{~cm}$ de largura e espessura de $50 \mathrm{~mm}$, com um desvio de planicidade de $0,5 \mathrm{~mm}$.

As propriedades termofísicas identificadas em laboratório para a condição seca são:

$\lambda_{\mathrm{o}}=0,840 \pm 0,044 \mathrm{~W} / \mathrm{m} \mathrm{K} ; \mathrm{e}$

$\rho_{\mathrm{o}} \cdot \mathrm{c}_{\mathrm{o}}=1906 \pm 21 \mathrm{~kJ} / \mathrm{m}^{3} \mathrm{~K}$.

Os ensaios em campo foram realizados durante o mês de junho de 2007 e, para esse período, o peso da amostra é de $9,795 \mathrm{~kg}$, o que corresponde a uma saturação estimada em $27,0 \%$. Para essa condição, as propriedades termofísicas foram estimadas em:

$\lambda_{\mathrm{m}}=0,978 \pm 0,065 \mathrm{~W} / \mathrm{m} \mathrm{K}$; e

$\rho_{\mathrm{o}} \cdot \mathrm{c}_{\mathrm{m}}=2.108 \pm 23 \mathrm{~kJ} / \mathrm{m}^{3} \mathrm{~K}$.

\section{Procedimento de medição}

$\mathrm{O}$ equipamento requerido para realizar as medições em campo é um equipamento simplificado, formado principalmente de termopares, transdutores de fluxo de calor, sistema de aquisição de dados e um microcomputador para registrar as leituras. A Figura 6 apresenta a configuração da bancada experimental para os ensaios em campo. 


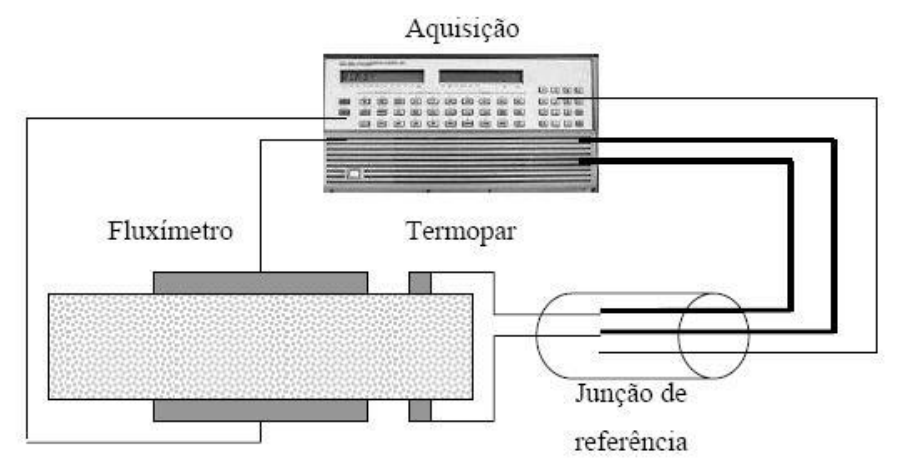

Figura 6 - Configuração para medição em campo

Como equipamento complementar, para caracterizar as condições climáticas para cada ensaio, utilizou-se um piranômetro (Maxwell modelo D3B, sensibilidade de $2 \mathrm{mV} / \mathrm{W} \mathrm{m}^{2}$ ) em posição vertical com orientação norte. A distribuição de temperatura na superfície norte da amostra foi conferida utilizando-se um sistema de medição de termografia infravermelha (câmara termográfica). O equipamento utilizado foi a câmera termográfica ThermaCam E25 da empresa Flir Systems com uma faixa de leitura de temperatura entre $-20^{\circ} \mathrm{C}$ e $250^{\circ} \mathrm{C}$.

Para a leitura das medições dos sensores, desenvolveu-se um programa em parceria com o Laboratório de Meios Porosos e Propriedades Termofísicas (LMPT). O programa permite que os dados de temperatura superficial, fluxo de calor superficial e radiação solar sejam lidos a cada $15 \mathrm{~s}$, ponderados em intervalos de $60 \mathrm{~s}$, e registrados em um microcomputador.

\section{Processamento de sinal}

Através do ensaio fluximétrico realizado previamente em laboratório com as amostras de concreto submetidas a estímulos periódicos de calor, foram observadas diferenças importantes entre os valores calculados pelo $\mathrm{kC}_{\text {úmido }} \mathrm{e}$ os medidos na bancada experimental (ORDENES, 2008). Outras experiências revelam a dificuldade para interpretar as variações de fluxo de calor quando não é considerada uma técnica de processamento de sinais (AKANDER, 2000; WEBER et al., 2005). Assim, é considerada uma técnica para o tratamento do sinal térmico (temperatura e fluxo de calor superficial) registrado no tempo.

As medições de temperatura e fluxo de calor superficial, decorrentes das condições climáticas, podem ser descritas por uma soma de componentes harmônicos que são múltiplos da frequência fundamental (DEFER et al., 2002; PFAFFEROTT;
HERKEL; WAPLER, 2005; WEBER et al., 2005; ZALEWSKI et al., 1997). Os dados obtidos a partir das medições podem ser descritos através da transformada de Fourier como um somatório de oscilações periódicas de diferentes frequências, de acordo com as Equações 15 e 16, em que T e q" são os valores médios para a temperatura e densidade de fluxo de calor, Tn e q"n são as amplitudes de oscilação dos diferentes componentes harmônicos, e $\omega n$ e $\varphi$ n representam a frequência angular e atraso para cada componente harmônico respectivamente.

$$
\begin{aligned}
& T(t)=\bar{T}+\sum_{n=1}^{N} T_{n} \cdot e^{i\left(\omega_{n} \cdot t+\varphi_{n}\right)} \\
& q^{\prime \prime}(t)=\overline{q^{\prime \prime}}+\sum_{n=1}^{N} q_{n}^{\prime \prime} \cdot e^{i\left(\omega_{n} \cdot t+\varphi_{n}\right)}
\end{aligned}
$$

Esse procedimento é utilizado também por Lü, Lu e Viljanen (2006). Porém, os autores selecionam aleatoriamente quatro períodos $(30,5,2$ e 1 dia) para descrever as variações de temperatura de ar externo medidas ao longo de um mês. No caso do procedimento adotado para o trabalho de pesquisa, os componentes harmônicos são organizados por amplitude de oscilação em ordem decrescente, para reconstituir as condições de contorno a serem utilizadas como dados de entrada no algoritmo de estimativa.

\section{Aplicação do método em campo}

\section{Bancada experimental}

A Figura 7 apresenta a montagem da bancada experimental no lugar selecionado para realizar todos os ensaios em campo. O local escolhido foi o brise com orientação norte no andar térreo do Bloco B do prédio de Engenharia Mecânica. A orientação desse local permite aumentar a radiação 
solar incidente no componente a estudar, e a localização garante condições de segurança e proteção contra a chuva para os sensores e conexões.

Para evitar a influência das variações de umidade em campo, aplicou-se na amostra uma película de resina acrílica incolor como impermeabilizante de alta resistência. A amostra também foi pintada com uma tinta preta, na tentativa de aumentar a influência da radiação solar incidente. Os sensores de temperatura e fluxo de calor aderidos à superfície da amostra também foram pintados com a mesma tinta preta para manter a mesma emissividade e evitar diferenças entre o fluxo de calor registrado pelo sensor e o calor que chega à superfície da amostra.

\section{Distribuição superficial de temperaturas}

A Figura 8 apresenta as imagens registradas pela câmara termográfica em paralelo com as imagens visuais do conjunto de amostra e sensores colocados em campo, indicando a posição do termopar (Tp) e o centro do transdutor de fluxo de calor (Flx).

Observa-se uma distribuição homogênea na região central da amostra, onde foram instalados os sensores de temperatura e fluxo de calor, com pouca diferença entre a temperatura superficial do fluxímetro e a da amostra $\left( \pm 0,7^{\circ} \mathrm{C}\right)$. Isso reflete uma baixa interferência do transdutor de fluxo de calor nas medições. As medições de temperatura superficial registradas pelo termopar no período em que foram captadas as imagens termográficas apresentam uma faixa de variação entre $31,1{ }^{\circ} \mathrm{C}$ e $32,7^{\circ} \mathrm{C}$. Isso é coerente com os valores registrados pela câmara termográfica para o mesmo período (12h00 às 12h20).

No entanto, a distribuição de temperaturas na superfície acusa um gradiente de temperatura na parte superior da amostra. Essa situação pode comprometer a condição de fluxo de calor unidirecional considerado como suposição no modelo de transferência de calor utilizado no programa $\mathrm{kC}_{\text {úmido }}$ Para conferir a condição de fluxo de calor unidirecional na amostra, foi utilizado o programa FEHT de análise de elementos finitos (INCROPERA; DEWITT, 2003), com o objetivo de realizar uma simulação bidimensional das condições internas na amostra, a partir das medições superficiais na amostra e das medições de temperatura do ar e radiação solar nela incidente. O programa FEHT utiliza o algoritmo de Crank-Nicolson para resolver a discretização de elementos finitos em $2 \mathrm{D}$, com uma capacidade de até 1.000 nós.

Figura 7 - Montagem da bancada experimental
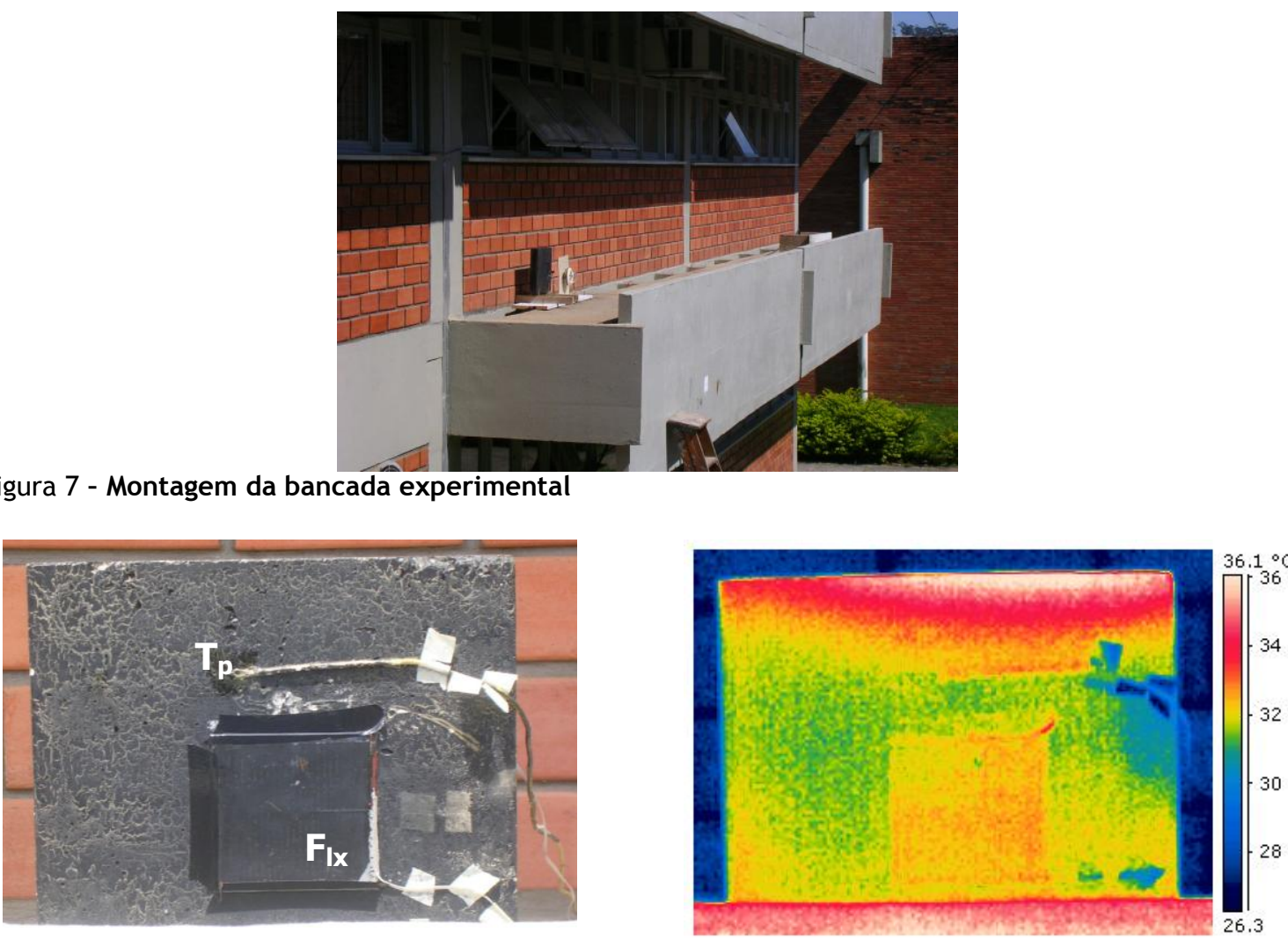

Figura 8 - Imagens visuais e termográficas registradas na superfície da amostra e sensores 
Para as simulações realizadas, definiu-se uma condutividade térmica de $1,0 \mathrm{~W} / \mathrm{m} \mathrm{K}$, um calor específico de $1.000 \mathrm{~J} / \mathrm{kg} \mathrm{K}$, e uma densidade aparente de $2.000 \mathrm{~kg} / \mathrm{m}^{3}$. O modelo elaborado para representar a seção transversal da amostra de concreto foi discretizado em elementos de $2,5 \mathrm{~mm}$ de espessura por $12,5 \mathrm{~mm}$ de altura.

A Figura 9 apresenta o gradiente de temperatura e linhas de fluxo de calor na seção transversal da amostra para os dias 28/06, 29/06, 14/07 e 15/07 às $12 \mathrm{~h} 30$, em que a radiação solar é mais intensa. Observa-se que a distorção no fluxo de calor acontece nos primeiros $50 \mathrm{~mm}$ a partir da superfície horizontal superior, sem alterar a condição de fluxo de calor unidirecional no centro da amostra, onde são colocados os sensores de temperatura e fluxo de calor.

\section{Processamento de sinal registrado em campo}

O acompanhamento das variações térmicas na amostra para a identificação de suas propriedades termofísicas foi realizado entre os dias 25 de junho e 17 de julho de 2007. Porém, nem todos os dias registrados nesse período foram utilizados na estimativa de propriedades termofísicas. Mesmo sendo aplicada uma película impermeabilizante na amostra, evitaram-se os dias sob condições de chuva. Assim, utilizaram-se como critério de seleção os dias em que não houvesse ocorrência de chuva nas $24 \mathrm{~h}$ anteriores ao início das medições.

A técnica de processamento de dados através da Transformada Discreta de Fourier permite decompor o sinal observado em 720 componentes harmônicos. No entanto, ao classificar os componentes por amplitude, é possível observar a participação que cada um deles tem na composição do sinal original. A Figura 10 apresenta a importância relativa que cada componente harmônico (tanto de temperatura como de fluxo de calor) tem em função da amplitude máxima $\left(\mathrm{A}_{\max }\right)$. Observa-se que apenas os 100 primeiros componentes contribuem significativamente na composição do sinal original. Os demais podem ser considerados como ruído do sinal.
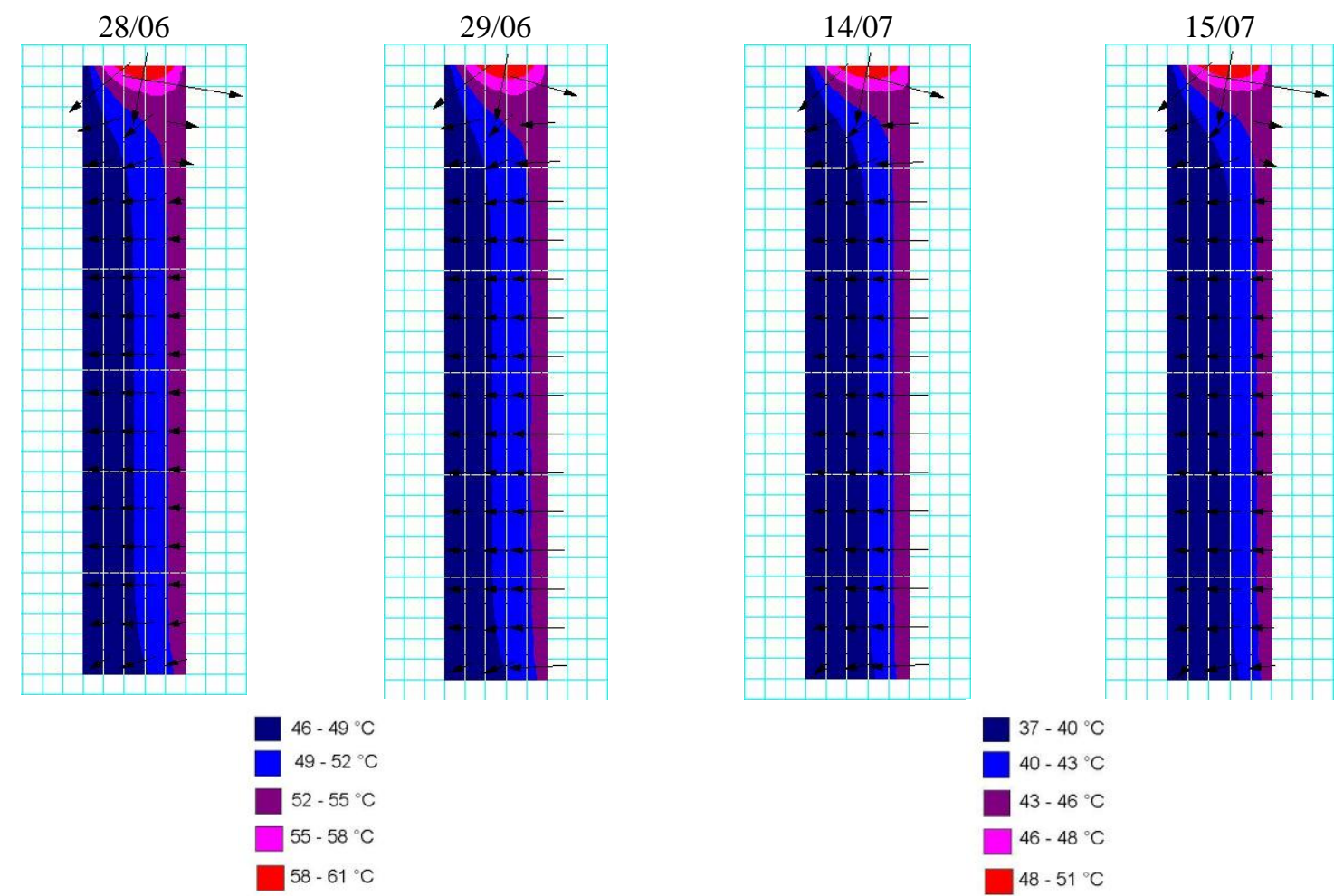

Figura 9 - Condições térmicas internas simuladas para a amostra de concreto nos dias de maior radiação solar 


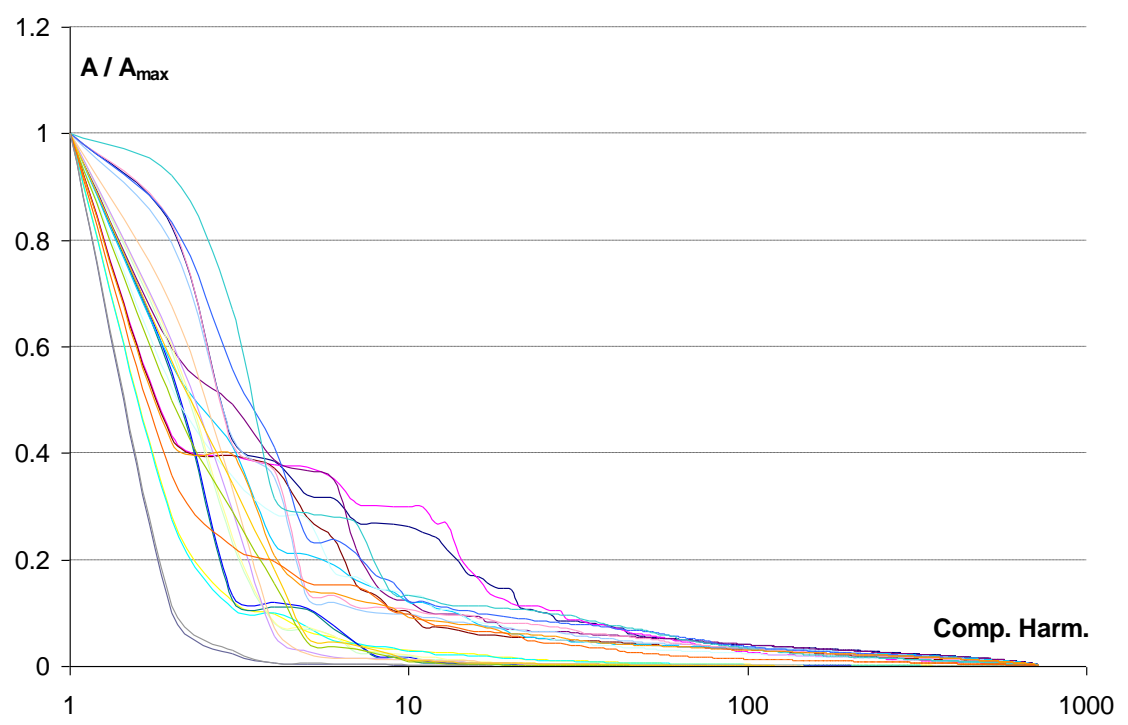

Figura 10 - Contribuição relativa dos componentes harmônicos
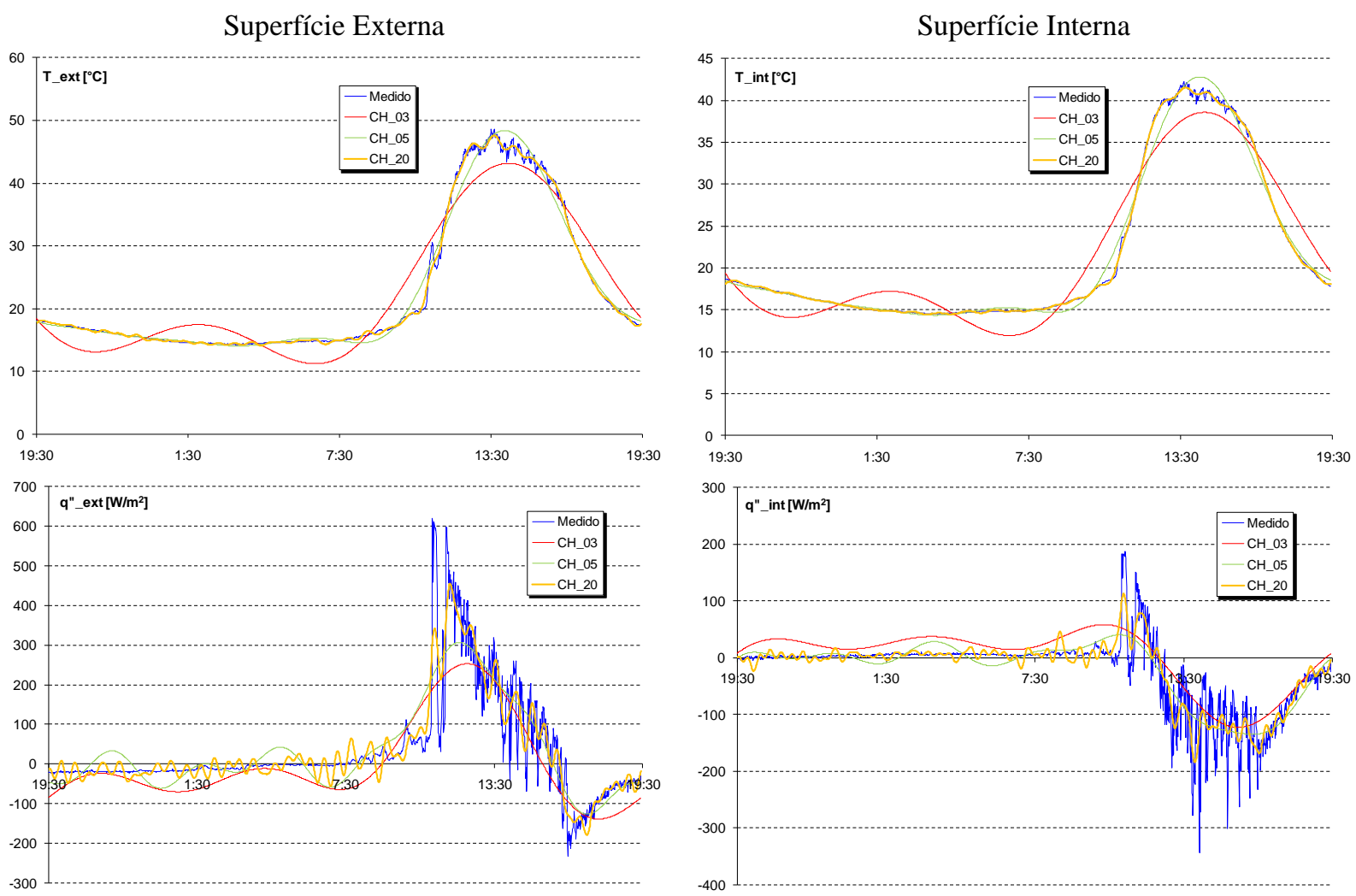

Figura 11 - Composição do sinal natural para o dia 15 de julho

Para ilustrar como exemplo, a Figura 11 apresenta a composição do sinal natural registrado no dia 15 de julho para os cinco e os vinte primeiros componentes harmônicos (curvas CH_05 e CH_20). Observa-se que, para as temperaturas superficiais, o somatório dos cinco primeiros componentes harmônicos representa bem o sinal original registrado, obtendo-se uma correlação de $99,3 \%$ para a superfície externa e de $99,5 \%$ para a superfície interna. Para a densidade de fluxo de calor, observa-se uma diferença importante tanto nos picos do dia como na condição estável à noite. Para o somatório dos cinco primeiros componentes harmônicos, a correlação é de $86,5 \%$ para a superfície externa e de $85,2 \%$ para a superfície interna. Porém, o aumento na quantidade de componentes harmônicos reconstitui um sinal com oscilações bruscas e ruído das trocas convectivas, 
o que pode trazer problemas de estabilidade computacional no algoritmo de estimativa das propriedades termofísicas.

\section{Estimativa de propriedades térmicas}

Os valores obtidos através do programa $\mathrm{kC}_{\text {úmido, }}$ a partir das medições em campo, são apresentados nas Figuras 12 e 13. Em cada gráfico também foram incluídos os limites máximo e mínimo, de acordo com a incerteza obtida previamente em laboratório (linhas tracejadas). $\mathrm{Na}$ análise completa, apresentada por Ordenes (2008), observa-se que, para um sinal de entrada com mais de 10 componentes harmônicos, as propriedades termofísicas estimadas não apresentam variações significativas. Para mostrar a influência da quantidade de componentes harmônicos, a estimativa é apresentada em base às medições em campo para os três e cinquenta primeiros componentes harmônicos (sequências HC_03 e HC_50 respectivamente). A Figura 12 apresenta os resultados para a condutividade térmica em condição seca $\left(\lambda_{\mathrm{o}}\right)$ e com uma saturação de $27 \%$ $\left(\lambda_{\mathrm{m}}\right)$. De forma análoga, a Figura 13 apresenta os resultados para a capacidade térmica volumétrica.

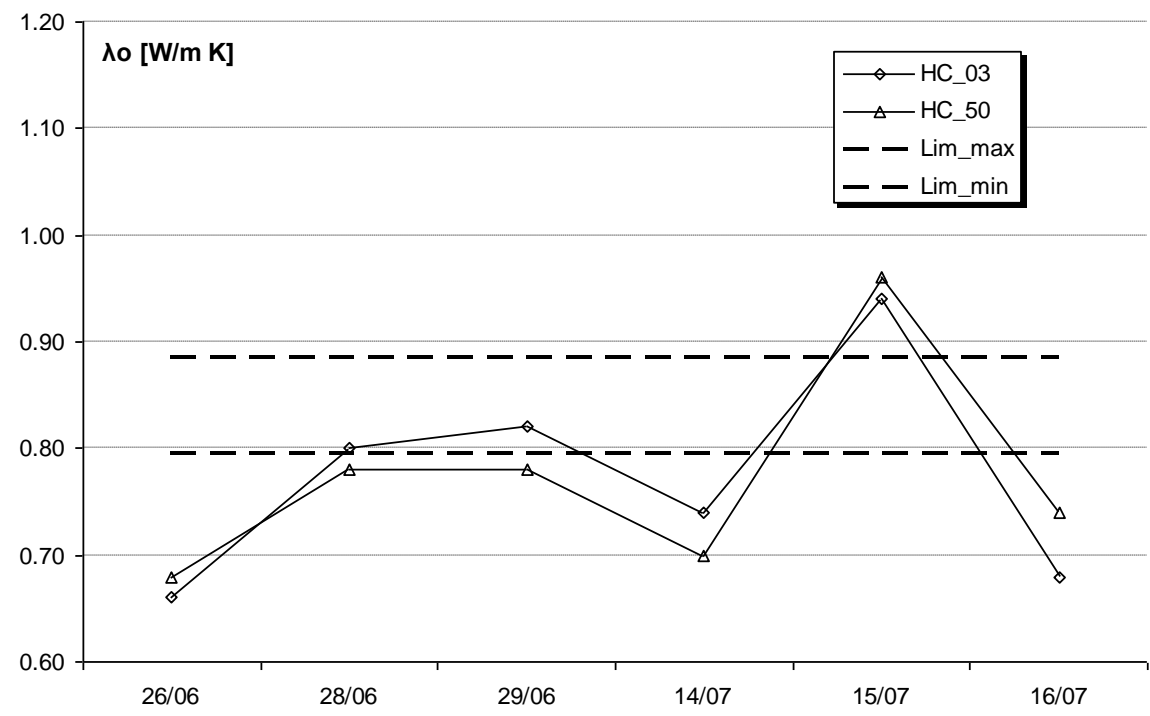

(a)

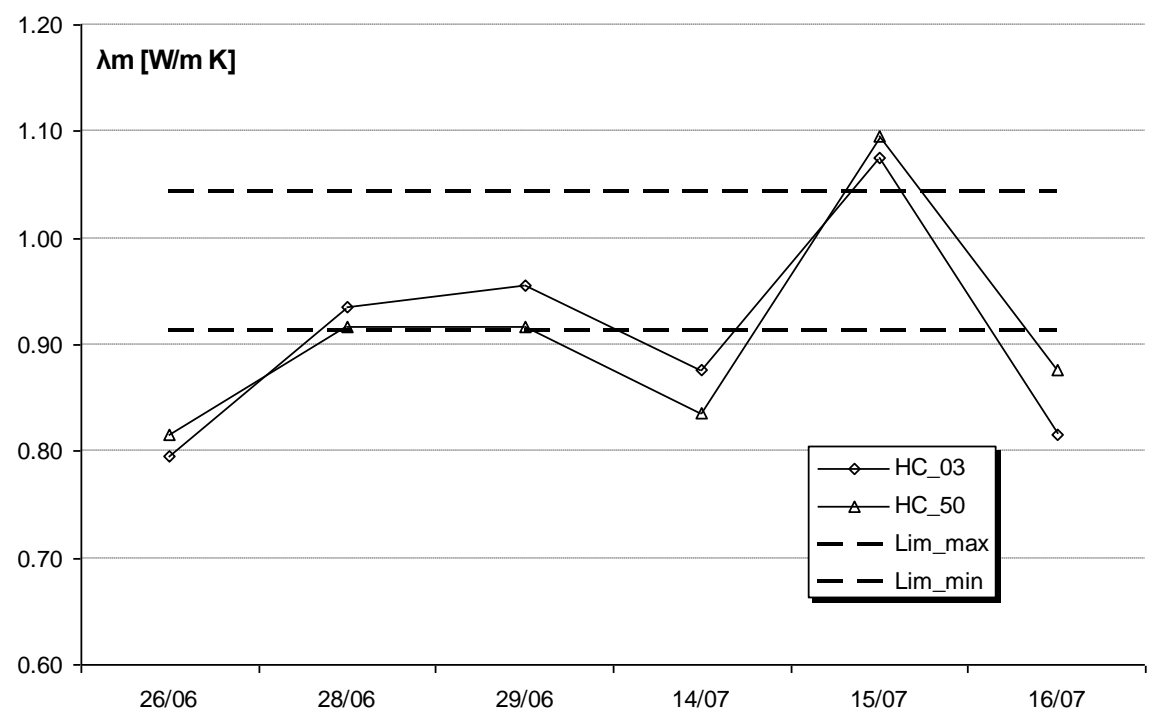

(b)

Figura 12 - Estimativa da condutividade térmica para a condição seca (a) e com saturação de $27 \%$ (b) 
Para a condutividade térmica, observa-se que os melhores resultados foram obtidos para os dias 28 e 29 de junho. Estes foram os dias com a maior incidência de radiação solar na superfície de amostra (1.400 e $1.300 \mathrm{~kJ}$ respectivamente). Para os dias com condição de céu nublado (26 de junho e 16 de julho, ambos com $100 \mathrm{~kJ}$ ), a estimativa apresenta resultados com uma diferença média de $0,15 \mathrm{~W} / \mathrm{m} \cdot \mathrm{K}$ se comparado com os valores previamente identificados em ensaios de laboratório.

Para a capacidade térmica volumétrica, os dias de céu nublado (26 de junho e 16 de julho) são os casos que apresentam maior dispersão nos valores obtidos para as duas superfícies e componentes harmônicos. Ainda, os valores obtidos apresentam uma diferença maior para essa propriedade termofísica se comparados com os resultados obtidos para a condutividade térmica.

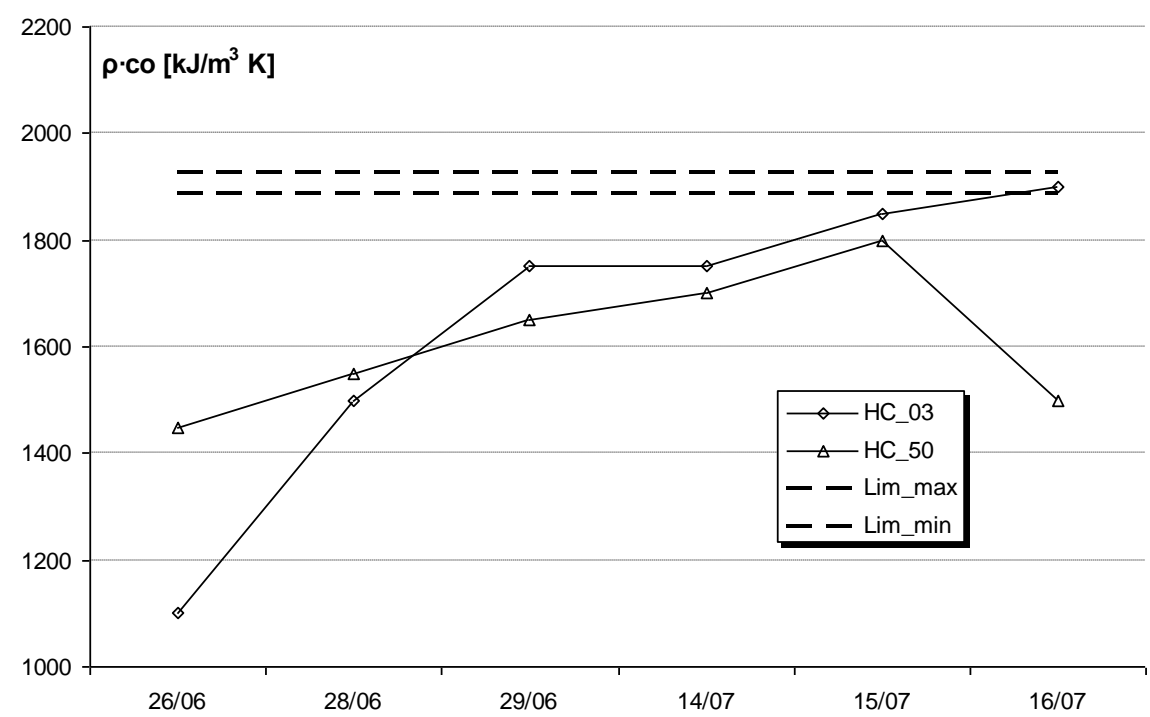

(a)

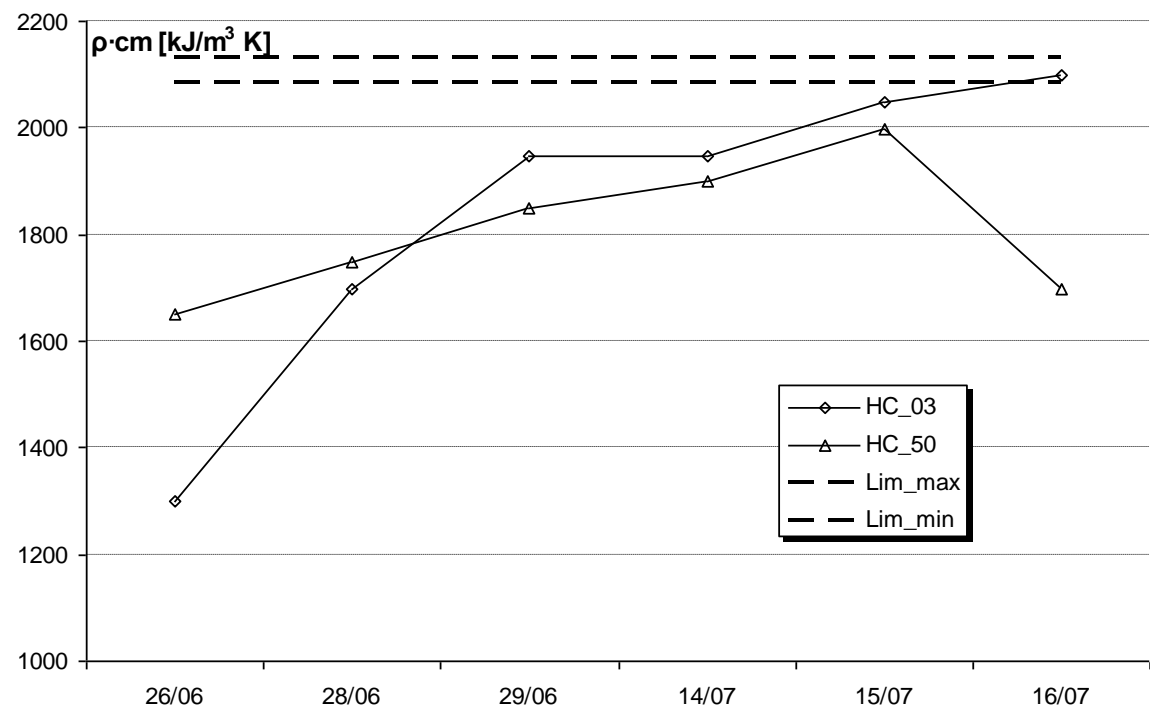

(b)

Figura 13 - Estimativa da capacidade térmica volumétrica para a condição seca (a) e com saturação de $27 \%$ (b) 


\section{Conclusões}

A solução por diferenças finitas para a equação de condução de calor pode ser utilizada para estabelecer uma relação entre as oscilações térmicas em cada superfície, para estimar as propriedades termofísicas de um componente homogêneo. Esse modelo matemático pode ser aplicado em campo aproveitando-se o sinal natural através de um equipamento para ensaio não destrutivo simplificado e de fácil aplicação.

A técnica de processamento de sinal utilizada para reduzir a influência das trocas convectivas (ruído no sinal) nas medições de fluxo de calor superficial é importante para evitar problemas de convergência e diminuir os recursos de processamento e tempo nos algoritmos de estimativa. Os principais componentes harmônicos observados nas medições são consistentes com a revisão bibliográfica.

Os resultados da estimativa mostram que o dia com céu nublado não forneceu informações suficientes para identificar as propriedades termofísicas. Isso destaca a importância da fonte de calor (radiação solar, no caso) no ensaio. Para os seis dias registrados, os resultados da estimativa apresentam uma diferença de $10-14 \%$ nas duas propriedades termofísicas se comparados com os valores obtidos em condições controladas de laboratório. Assim, os resultados obtidos mostram que essa ferramenta não deve ser entendida como um método de precisão que substitua os ensaios de laboratório, conhecidos e validados, e sim como um complemento aos procedimentos de estimativa de propriedades termofísicas.

Embora a pesquisa considere uma análise de componentes construtivos homogêneos, é importante apontar que a grande maioria dos componentes usados atualmente na construção são não homogêneos. O presente trabalho de pesquisa pretende começar com uma amostra homogênea de material comumente usado na construção para facilitar a metodologia e os parâmetros a analisar. Porém, os modelos matemáticos adotados permitem trabalhar com componentes multicamadas e propriedades termofísicas equivalentes. Outra limitação do trabalho é a adoção dos coeficientes de transporte de umidade apresentados por Perrin (1985). Assim, precisamse pesquisas complementares para estabelecer uma biblioteca com as propriedades de materiais utilizados comumente na construção civil. Ainda, os resultados preliminares obtidos no estudo são um incentivo importante para melhorar o método.

\section{Referências}

AKANDER, J. The ORC Method: effective modeling of thermal performance of multiplayer building components. 2000. $178 \mathrm{f}$. Tese (Doutorado) - Department of Building Sciences, Kungl Tekniska Högskolan, Sweden, 2000.

\section{ASSOCIAÇÃO BRASILEIRA DE NORMAS}

TÉRCNICAS. NBR 15220-4: desempenho térmico de edificações: parte 4: medição da resistência térmica e da condutividade térmica pelo princípio da placa quente protegida. Rio de Janeiro, 2005. 10 p.

BECK, J; PETRIE, T; COURVILLE, G. Using Parameter Estimation to Analyze Building Envelope Thermal Performance. In-Situ Heat Flux Measurements in Buildings: applications and interpretations of results. Hanover: U.S. Army Cold Regions Research and Engineering Laboratory, 1991. p. 161-191. Special Report 91-3.

BORGES, V. L.; LIMA E SILVA, S.; GUIMARÃES, G. A Dynamic Thermal Identification Method: part I, non conductor solid materials. Inverse Problems, Design and Optimization Symposium, Rio de Janeiro, v. 14, n. 5, p. 511-527, 2006.

CONDON, P.; CARROL, R.; SONDEREGGER, R. A New Measurement Strategy for in-Situ Testing of Wall Thermal Performance.

California: Lawrence Berkeley Laboratory, 1979.

DEFER, D. et al. Non-Destructive Testing of a Building Wall by Studying Natural Thermal Signs. Energy and Buildings, v. 34, n. 1, p. 63-69, 2002.

DIMOUDI, A.; LYKOUDIS, S.; ANDROUTSOPOULOS, A. Thermal Performance of an Innovative Roof Component. Renewable Energy, v. 31, n. 14, p. 2257-2271, dez. 2006.

GUSTAFSSON, S. Transient Plane Source Techniques for Thermal Conductivity and Thermal Diffusivity Measurements of Solids Materials. Review of Scientific Instruments, v. 62, n. 3, p. 797-805, 1990.

HARALAMBOPOULOS, D.; PAPARSENOS, G. Assessing the Thermal Insulation of Old Buildings: the need for in-situ spot measurements of thermal resistance and planar infrared thermography. Energy Conversion and Management, v. 31, n. 1/2, p. 65-79, 1998. 
INCROPERA, F.; DEWITT, D. Transferência de Calor e Massa. 5. ed. Rio de Janeiro: Livros Técnicos e Científicos Editora, 2003.

\section{INTERNATIONAL ORGANIZATION FOR} STANDARDIZATION. ISO 9869: thermal Insulation: building elements, in-situ measurement of thermal resistance and thermal transmittance. 1994.

LÜ, X.; LU, T.; VILJANEN, M. A New

Analytical Method to Simulate Heat Transfer Process in Buildings. Applied Thermal Engineering, v. 26, n. 16, p. 1901-1909, nov. 2006.

MICHELS, C.; LAMBERTS, R.; GUTHS, S. Evaluation of Heat Flux Reduction Provided by the Use of Radiant Barriers in Clay Tile Roofs. Energy and Buildings, v. 40, n. 16, p.445-451, 2008.

NICOLAJSEN, A. Thermal Transmittance of a Cellulose Loose-Fill Insulation Material. Building and Environment, v. 40, n. 7, p. 907-914, 2005.

ORDENES, M. Estimativa de Propriedades Termofísicas Através da Análise de Sinal Natural com Modelos de Transferência de Calor e Umidade. 2008. Tese (Doutorado em Engenharia Civil) - Escola de Engenharia, Universidade Federal de Santa Catarina, Florianópolis, 2008.

PERRIN, B. Étude des Transfers Couplés de Chaleur et de Masse dans des Matériaux Poureux Consolidés Non Saturés Utilisés en Génie Civil. 1985. 267 f. Tese (Doutorado em Engenharia Civil) - Université Paul Sabatier, Toulouse, 1985.
PFAFFEROTT, J.; HERKEL, S.; WAPLER, J. Thermal Building Behaviour in Summer: longterm data evaluation using simplified models. Energy and Buildings, v. 37, n. 8, p. 844-852, ago. 2005.

PHILIP, J. R.; DE VRIES, D. A. Moisture Mouvement in Porous Material Under Temperature Gradients. Transactions of the American Geophysucal Union, v. 38, p. 222-232, 1957.

TAKAHASHI, I. et al. Development of a Thermophysical Handy Tester for Non-Destructive Evaluation of Engineering Materials.

International Journal of Thermophysics, v. 25, n. 5, p. 1597-1610, set. 2004.

WEBER, T. et al. Validation of a FEM-Program (Frequency-domain) and a Simplified RC-Model (Time-Domain) for Thermally Activated Building Component Systems (TABS) Using Measurement Data. Energy and Buildings, v. 37, n. 7, p. 707724, 2005.

ZALEWSKI, L. et al. Experimental Thermal Study of a Solar Wall of Composite Type. Energy and Buildings, v. 25, n. 1, p. 7-18, 1997.

\section{Agradecimentos}

Os autores agradecem ao programa de intercâmbio PEC-PG entre a CAPES (Brasil) e a CONICYT (Chile) pelo apoio financeiro da pesquisa. 